\title{
Performance of Ship Assistance Program for Fisheries
}

\author{
Mira \\ The Center for Socioeconomic Research, Ministry of Marine Affairs and Fisheries, \\ Republic of Indonesia \\ Jl. Prof. Soedarto, S.H., Semarang 50275, Jawa Tengah, Indonesia \\ E-mail address: miraclenia@yahoo.com
}

\begin{abstract}
The purpose of this study identify inhibiting factors that make the program Inka Mina did not reach goal. The study uses regression analysis and correlation analysis. Correlation analysis results indicate that the strong correlation between the number of aid ships with determining factors such as the potential for fisheries, the number of fishermen, the amount of production, the number of ship, number of $K U B$, and the fishing port. Regression analysis results indicate that amount of aid ships in a region is in accordance with the elements set out in the technical guidance. However, a strong correlation does not necessarily determine the success of this program, because there are other factors that have not been considered (qualitative factors), such as culture one day fishing on coastal communities, people's habits (gear and type of size), transfer knowledge, and other factors. Assessment for this problem, government should consider the culture aspect.
\end{abstract}

Keywords: productivity, group, regression, correlation,

JEL Classification Codes: O1, O2

\section{Keragaan Program Kapal Bantuan Perikanan}

\begin{abstract}
Abstrak
Penelitian ini bertujuan; pertama, membandingkan model pengelolaan sumber daya perikanan dengan versi konvensional dan yang berparadigma baru; kedua, mengeksplorasi tingkat keberhasilan model pengelolaan sumberdaya perikanan dengan paradigma baru; dan ketiga menyusun strategi pengelolaan sumberdaya perikanan berbasis ekosistem (EBFM). Ekosistem Karimunjawa yang merupakan wilayah kepulauan yang dapat diambil menjadi pilot project. Tokoh kunci sebanyak 25 orang yang diambil secara purposive quoted sampling. Deskriptif statistik dipakai untuk menganalisis data penelitian dan juga dilengkapi dengan metode MetaAnalysis dan Analysis Hierarchy Proccess. Hasil penelitian menunjukkan bahwa model pengelolaan secara konvensional masih belum berhasil dalam mengelola sumberdaya. Sedangkan, pengelolaan sumberdaya perikanan berbasis ekosistem memberikan indikasi yang prospektif. Untuk itu disarankan perlu diuji-coba implementasinya. Bila model EBFM yang diusulkan ini telah lolos uji maka kerangka implementasi EBFM ini diharapkan dapat diadopsi oleh daerah lain di Indonesia untuk mengelola sumber daya perikanannya.
\end{abstract}

Kata kunci: produktivitas, kelompok, regresi, korelasi, masyarakat pesisir

Kode Klasifikasi JEL: O1, O2 


\section{Pendahuluan}

Masyarakat pesisir identik dengan kemiskinan dan kekumuhan. Hal ini bisa dilihat dari kondisi rumah masyarakat pesisir yang masih banyak dalam bentuk semi permanen. Menurut hasil penelitian Panelkanas pada tahun 2012 menunjukkan 35 persen kondisi rumah nelayan dalam bentuk semi permanen. Bahkan data yang dirilis Badan Pusat Statistik (BPS) pada tahun 2008 mengenai tingkat kemiskinan membenarkan fakta bahwa masyarakat pesisir identik dengan kemiskinan. Pada tahun 2008 ada 34,96 juta penduduk miskin, di mana 63,47 persen berada pada kawasan pesisir.

Mengentaskan kemiskinan di masyarakat pesisir menjadi salah satu program dari Kementerian Kelautan dan Perikanan, oleh karena itu dalam upaya meningkatkan pendapatan dan kesejahteraan masyarakat perikanan, Kementerian Kelautan dan Perikanan mengoptimalkan Program Nasional Pemberdayaan Masyarakat Mandiri (PNPM) melalui Pengembangan Usaha Mina Perdesaan (PUMP) dan Pemberdayaan Usaha Garam Rakyat (PUGAR). PUMP terbagi ke dalam dua sektor yaitu sektor perikanan tangkap, sektor garam, dan sektor perikanan budidaya, dan program bantuan kapal 30 GT.

Khusus program bantuan kapal 30 GT diharapkan sebagai motor pemberdayaan masyarakat dan pengentasan kemiskinan di masyarakat pesisir. Adapun salah satu caranya adalah peningkatan produksi, produktifitas, dan penyerapan tenaga kerja di masyarakat pesisir melalui program bantuan yang diberikan berupa kapal. Khususnya tujuan program ini adalah memperkuat Armada Perikanan Nasional dalam rangka mendukung program ketahanan pangan, menjaga wilayah NKRI dan meningkatkan kesejahteraan masyarakat nelayan. Banyak kapal program bantuan yang tidak beroperasi setelah serah terima dengan penerima bantuan. Misalnya dari INKA MINA yang disalurkan pada tahun 2010, berdasarkan hasil monitoring per 3 November 2012, ada 6 kapal yang disalurkan tidak dapat beroperasi, seperti di Kalimantan Selatan (Kota Baru), Papua Barat (Sorong dan Manokwari), Sumbar (Pesisir Selatan), Nusa Tenggara Timur (Ende), dan Maluku Tenggara. Kesimpulannya adalah program Inka Mina belum mencapai tujuannya. Permasalahan apa yang menyebabkan kapal bantuan tersebut tidak beroperasi dan bagaimana assessmentnya itulah tujuan dari penelitian ini.

\section{Metode Penelitian}

\section{Lokasi dan Waktu Penelitian}

Lokasi kegiatan adalah wilayah yang menerima bantuan Inka Mina pada tahun 2010 dan 2011, namun untuk kasusnya dipilih Pelabuhan Ratu (mewakili pulau Jawa), Manokwari (Timur Indonesia), dan Padang Pariaman (Indonesia Bagian Barat). Penelitian dilakukan pada tahun 2012.

\section{Jenis dan Sumber Data}

Data dikumpulkan dalam bentuk data sekunder dan data primer. Data primer berupa wawancara dengan Direktorat Jenderal Perikanan Tangkap (DJPT), KUB pengelola, anggota KUB penerima, dan Bapak Angkat KUB pengelola, dan penyuluh dan pendamping yang berasal dari kasus yaitu Pelabuhan Ratu, Padang Pariaman, dan Monokwari. Jumlah responden untuk data primer adalah sebanyak 19 orang dimana dari pihak DJPT kuesioner diisi oleh 3 orang, dari Pelabuhan Ratu sebanyak 10 responden yang meliputi dari pihak Dinas Kelautan Perikanan, Ketua KUB, anggota KUB, dan Bapak Angkat. Sedangkan untuk wilayah Padang Pariaman dan Monokwari jumlah responden yang diperoleh hanya 3 orang. Pengambilan jumlah responden dilakukan secara snowball di mana pihak dinas kelautan dan perikanan dan ketua KUB diperoleh dari saran DJPT, sedangkan untuk pihak anggota, ABK, dan Bapak angkat diperoleh saran dari pihak Dinas Kelautan dan Perikanan dan Ketua KUB. Adapun data sekunder diperoleh dari Direktorat Jenderal Perikanan Tangkap (DJPT). Data sekunder digunakan untuk analisis regresi dan analisis korelasi, dimana sampelnya berupa 11 wilayah yang memiliki kelengkapan kelengkapan data yang sesuai dengan kriteria pemberian bantuan yang ditetapkan oleh DJPT. Adapun kriteria pemberian bantuan oleh DJPT berdasarkan pertimbangan jumlah produksi, jumlah nela- 
yan, jumlah kapal, potensi perikanan tangkap laut, jumlah pelabuhan dan jumlah KUB.

\section{Metode Analisis Data}

\section{Analisis Korelasi}

Analisis korelasi adalah analisis yang digunakan untuk menunjukkan ada atau tidaknya hubungan antara kejadian yang satu dengan kejadian lainnya. Jadi jelas, analisis korelasi memungkinkan kita untuk mengetahui sesuatu di luar hasil kejadian. Hubungan antara dua variabel ada yang positif dan ada yang negatif. Hubungan X1, X2, X3, X4, X5, X6 dan Y dikatakan positif apabila kenaikan X1, X2, X3, X4, X5, $X 6$ pada umumnya diikuti oleh kenaikan $Y$ atau sebaliknya. Hubungan X1, X2, X3, X4, X5, X6 dan $Y$ dikatakan negatif kalau kenaikan $X 1, X 2$, X3, X4, X5, X6 diikuti penurunan Y. Jika naik/turunnya variabel $x$ tidak mempengaruhi Y, dikatakan X1, X2, X3, X4, X5, X6 dan Y bebas (independen) atau tidak ada hubungan atau hubungannya begitu lemah sehingga bisa diabaikan.

Kuat atau tidaknya hubungan antara $X 1$, $\mathrm{X} 2, \mathrm{X} 3, \mathrm{X} 4, \mathrm{X} 5, \mathrm{X} 6$ dan $\mathrm{Y}$ dapat dinyatakan dengan fungsi linier, diukur dengan suatu nilai yang disebut koefisien korelasi. Nilai koefisien korelasi ini paling sedikit -1 dan paling besar 1 . Jika nilai Pearson correlation $=1$, hubungan $\mathrm{X} 1$, $\mathrm{X} 2, \mathrm{X} 3, \mathrm{X} 4, \mathrm{X} 5, \mathrm{X} 6$ dan $\mathrm{Y}$ sempurna dan positif (mendekati 1, yaitu hubungan sangat kuat dan positif). Jika nilai Pearson correlation $=-1$, hubungan $\mathrm{X} 1, \mathrm{X} 2, \mathrm{X} 3, \mathrm{X} 4, \mathrm{X} 5, \mathrm{X} 6$ dan $\mathrm{Y}$ sempurna dan negatif (mendekati -1 , yaitu hubungan sangat kuat dan negatif). Jika nilai pearson correlation $=0$, hubungan $X 1, X 2, X 3$, X4, X5, X6 dan Y lemah sekali atau tidak ada hubungan. Besarnya kontribusi dari X1, X2, X3, $\mathrm{X} 4, \mathrm{X} 5, \mathrm{X} 6$ terhadap naik turunnya nilai $\mathrm{Y}$ dinyatakan dengan suatu koefisien yang disebut koefsien penentuan Pearson correlation.

\section{Analisis Regresi}

Analisis Regresi dapat dipergunakan untuk memperlihatkan keterkaitan antarvariabel. Pada analisis regresi akan dicari seberapa besar pengaruh sebuah variabel pada variabel lain (Santoso, 2001). Analisis regresi linear dapat dilakukan dengan bantuan program SPSS. Adapun tahap-tahap analisisnya adalah sebagai berikut:
Pertama, menentukan variabel-variabel yang akan digunakan

Kedua, Mengumpulkan data-data yang dibutuhkan sebagai variabel X1, X2, X3, X4, X5, dan X6 dan Y.

Ketiga, Melakukan perhitungan secara komputerisasi dengan menggunakan bantuan SPSS.

Melalui program SPSS tersebut, kita dapat melakukan uji statistik dengan menggunakan standar penguji hasil regresi, antara lain:

\section{Uji F untuk signifikasi menyeluruh.}

Uji F digunakan untuk membandingkan antara hasil analisis yang didapatkan dengan kenyataan yang ada di lapangan. Jika $\mathrm{F}$ hitung lebih besar daripada $\mathrm{F}$ tabel, maka regresinya bersifat nyata atau dapat diterapkan di lapangan. Begitu juga sebaliknya.

\section{Uji Koefisien Determinasi $\left(R^{2}\right)$}

Koefisien determinan digunakan untuk mengetahui tingkat keberhasilan antara variabel bebas dan terikat. Nilai R2 berada di antara 0-1. Jika nilai R2 mendekati 0 menyatakan bahwa model tersebut kurang mencakup keseluruhan variabilitas dengan variabel-variabel yang dispesifikasikan dalam model. Jika R2 $=0$ menyatakan bahwa tidak ada hubungan antara variabel terikat dan variabel bebas. Jika R2 $=1$ menyatakan bahwa nilai observasi berada pada garis regresi.

Untuk mengetahui hubungan $\mathrm{X}$ dan $\mathrm{Y}$ digunakan koefisien korelasi (R). Nilai R berkisar antara-1 dan 1. Jika nilai $R$ mendekati 1 atau -1 maka akan makin baik data atau sampel yang diterangkan oleh persamaan regresi. Jika nilainya mendekati 0 maka data yang diterangkan makin tidak baik. Jika nilai $\mathrm{R}=1$ atau $\mathrm{R}=$ 1 , maka segala variabel $\mathrm{Y}$ diterangkan dengan sempurna oleh variabel $X$.

\section{Uji t untuk signifikasi individu}

Fungsi dari pengujian ini adalah untuk menguji variabel bebas dalam menerangkan variabel terikat. Pengujiam ini dilakukan dengan memperhatikan kehadiran regresor (variabel bebas). Analisis uji $t$ ini bisa menggunakan taraf signifikasi $1 \%$.

4. Uji koefisien didasarkan pada nilai konstanta (koefisien a) atau nilai fasek (koefisien b), yang didasarkan print out data SPSS hasil perhitungan data-data. 


\section{Hasil dan Pembahasan}

\section{Analisis Korelasi}

Sebelum menganalisis faktor-faktor penghambat program kapal perikanan 30 GT, sebaiknya melihat faktor-faktor yang menjadi pertimbangan di Pedum (Pedoman Umum) dalam pemberian bantuan di suatu lokasi. Hal ini dilakukan banyaknya kapal yang disalurkan tidak termanfaatkan. Berdasarkan hasil wawancara dengan pihak Direktorat Jenderal Perikanan Tangkap (DJPT) pada November 2012, banyak faktor yang menjadi pertimbangan dalam jumlah pemberian bantuan pada setiap provinsi, seperti potensi perikanan pada setiap daerah, jumlah nelayan, jumlah produksi, jumlah kapal, jumlah KUB (Kelompok Usaha Bersama), jumlah pelabuhan perikanan. Berdasar variabel yang ditetapkan oleh DJPT tersebut kemudian data diolah menggunakan analisis korelasi.

Analisis ini digunakan apabila variabelvariabel yang ditetapkan oleh DJPT dalam pemberian bantuan berkorelasi secara statistik. Tampilan output SPSS pada Tabel 1, memperlihatkan bahwa lima varibel independen menunjukkan korelasi yang positif dan kuat, terlihat variabel independen yang berkorelasi positif dan kuat adalah jumlah potensi sumberdaya ikan, jumlah produksi, jumlah KUB, jumlah nelayan, jumlah pelabuhan, dan jumlah kapal. Dimana masing-masing nilai korelasi tersebut adalah 0,$67 ; 0,69 ; 0,69 ; 0,89 ; 0,93$; dan 0,62 . Korelasi tersebut dikatakan kuat karena nilai korelasinya di atas 0,5 .

Variabel yang berkorelasi sangat kuat dengan jumlah pemberian bantuan adalah jumlah nelayan. Bantuan berupa kapal 30 GT ke atas karena untuk mengoptimalkan pemanfaatan Zona Ekonomi Eklusif (ZEEI). Selama ini di kawasan ZEEI banyak terjadi illegal fishing yang dilakukan oleh nelayan asing, karena sumberdaya ikan di kawasan tersebut belum dimanfaatkan secara optimal. Hal ini disebabkan karena masalah klasik dalam sebuah usaha yaitu besarnya modal yang dibutuhkan untuk membeli kapal 30 GT, mesin, dan alat tangkapnya.

Korelasi yang kuat antara jumlah pemberian bantuan dengan faktor yang mempengaruhinya belum tentu menentukan keberhasilan program ini. Hal ini disebabkan ada faktor lainnya yang belum dipertimbangkan oleh DJPT, faktor tersebut misalnya adalah budaya one day fishing pada masyarakat pesisir, transfer knowledge, dan faktor lainnya. Faktor-faktor inilah yang menjadi penghambat keberhasilan pelaksanaan program selama ini. Assessment terhadap masalah ini, pada waktu yang akan datang pihak DJPT akan memasukan variabel lainnya seperti budaya one day fishing, kebiasaan masyarakat terhadap alat tangkap dan ukuran kapan dan transfer knowledge.

Selain itu, menurut DJPT faktor yang tidak kalah penting lainnya adalah kerjasama dari Pemda Provinsi dan Kabupaten dalam memberikan hasil evaluasi dan monitoring dari program bantuan ini. Pada tahun 2010, Pemda yang sangat kurang kerja samanya adalah Pemda Trenggalek, Tuban, Pacitan, Berau, Pamekasan, Rokan Hilir, DKI Jakarta, Subang, Sumut, dan DIY. Kurangnya kerja sama itu terlihat dari tidak ada balasan e-mail atau sms ketika DJPT meminta hasil evaluasi terhadap program ini.

Adapun assesment terhadap Pemda yang mangkir dari tanggung jawabnya adalah pihak DJPT tidak akan mengurangi alokasi kapal kepada daerah tersebut. Pada tahun 2011, berdasarkan data dari pihak DJPT, Pemda yang tidak jadi dialokasikan untuk program kapal bantuan 30 GT ini adalah Asahan dan Bali. Ada juga Pemda yang menyatakan ketidaksanggupannya dalam mengelola program ini. Adapun kabupaten tersebut adalah Kabupaten Batubara, Tulung Agung, Kota Makasar, Tuban, Pacitan, Blitar, Lombok Utara, dan kota Bima.

Program INKA MINA dari DJPT KKP juga diharapkan mengutamakan wilayah perbatasan. Berdasarkan data yang ada, contohnya untuk lokasi Kabupaten Natuna tidak ada bantuan terkait program tersebut sejak tahun 2010 hingga 2012. Pengutamaan wilayah perbatasan juga selaras dengan tujuan program INKA MINA yaitu mengoptimalkan penangkapan di wilayah ZEEI, terutama di wilayah perbatasan yang selama ini banyak menjadi praktek illegal fishing. Saat ini dengan perahu nelayan di wilayah perbatasan yang ukuran hanya 5 GT maka wilayah penangkapan hanya 
Tabel 1. Korelasi Antar Faktor Pertimbangan

\begin{tabular}{|c|c|c|c|c|c|c|c|c|}
\hline & & $\begin{array}{l}\text { Jumlah } \\
\text { bantuan }\end{array}$ & Potensi & Produksi & KUB & Nelayan & Kapal & Pelabuhan \\
\hline \multirow{2}{*}{$\begin{array}{l}\text { Jumlah } \\
\text { bantuan }\end{array}$} & \multirow{2}{*}{$\begin{array}{l}\text { Pearson } \\
\text { Correlation } \\
\text { Sig. (2-tailed) } \\
\mathrm{N} \\
\text { Pearson }\end{array}$} & 1 & 0,66537426 & 0,690933 & 0,689744 & 0,886835 & 0,928857 & 0,618031211 \\
\hline & & 11 & $\begin{array}{l}0,02545758 \\
11\end{array}$ & $\begin{array}{l}0,018559 \\
11\end{array}$ & $\begin{array}{l}0,018847 \\
11\end{array}$ & $\begin{array}{l}0,000274 \\
11\end{array}$ & $\begin{array}{l}3,61 \mathrm{E}-05 \\
11\end{array}$ & $\begin{array}{l}0,042710611 \\
11\end{array}$ \\
\hline \multirow[t]{2}{*}{ Potensi } & & 0,665374261 & 1 & 0,815577 & 0,150825 & 0,602424 & 0,604667 & 0,317220561 \\
\hline & $\begin{array}{l}\text { Sig. (2-tailed) } \\
\mathrm{N} \\
\text { Pearson }\end{array}$ & $\begin{array}{l}0,025457576 \\
11\end{array}$ & 11 & $\begin{array}{l}0,002212 \\
11\end{array}$ & $\begin{array}{l}0,658009 \\
11\end{array}$ & $\begin{array}{l}0,049829 \\
11\end{array}$ & $\begin{array}{l}0,048759 \\
11\end{array}$ & $\begin{array}{l}0,341839784 \\
11\end{array}$ \\
\hline Produksi & $\begin{array}{l}\text { Correlation } \\
\text { Sig. (2-tailed) } \\
\text { N }\end{array}$ & $\begin{array}{l}0,690933296 \\
0,018559218 \\
11\end{array}$ & $\begin{array}{l}0,8155772 \\
0,00221197 \\
11\end{array}$ & $\begin{array}{l}1 \\
11\end{array}$ & $\begin{array}{l}0,384255 \\
0,243303 \\
11\end{array}$ & $\begin{array}{l}0,713656 \\
0,013652 \\
11\end{array}$ & $\begin{array}{l}0,643975 \\
0,032488 \\
11\end{array}$ & $\begin{array}{l}0,671508118 \\
0,023659401 \\
11\end{array}$ \\
\hline \multirow{2}{*}{ KUB } & $\begin{array}{l}\text { Pearson } \\
\text { Correlation }\end{array}$ & 0,689743817 & 0,15082517 & 0,384255 & 1 & 0,604672 & 0,611637 & 0,696443108 \\
\hline & $\begin{array}{l}\text { Sig. (2-tailed) } \\
\mathrm{N} \\
\text { Pearson }\end{array}$ & $\begin{array}{l}0,018846556 \\
11\end{array}$ & $\begin{array}{l}0,65800916 \\
11\end{array}$ & $\begin{array}{l}0,243303 \\
11\end{array}$ & 11 & $\begin{array}{l}0,048757 \\
11\end{array}$ & $\begin{array}{l}0,045536 \\
11\end{array}$ & $\begin{array}{l}0,017268962 \\
11\end{array}$ \\
\hline Nelayan & $\begin{array}{l}\text { Correlation } \\
\text { Sig. (2-tailed) } \\
\mathrm{N} \\
\text { Pearson }\end{array}$ & $\begin{array}{l}0,886834939 \\
0,000273668 \\
11\end{array}$ & $\begin{array}{l}0,60242364 \\
0,04982928 \\
11\end{array}$ & $\begin{array}{l}0,713656 \\
0,013652 \\
11\end{array}$ & $\begin{array}{l}0,604672 \\
0,048757 \\
11\end{array}$ & $\begin{array}{l}1 \\
11\end{array}$ & $\begin{array}{l}0,951086 \\
6,9 \mathrm{E}-06 \\
11\end{array}$ & $\begin{array}{l}0,703259449 \\
0,01576328 \\
11\end{array}$ \\
\hline \multirow[t]{2}{*}{ Kapal } & $\begin{array}{l}\text { Correlation } \\
\text { Sig. (2-tailed) } \\
\text { N }\end{array}$ & $\begin{array}{l}0,92885746 \\
3,60712 \mathrm{E}-05 \\
11\end{array}$ & $\begin{array}{l}0,60466679 \\
0,04875937 \\
11\end{array}$ & $\begin{array}{l}0,643975 \\
0,032488 \\
11\end{array}$ & $\begin{array}{l}0,611637 \\
0,045536 \\
11\end{array}$ & $\begin{array}{l}0,951086 \\
6,9 \mathrm{E}-06 \\
11\end{array}$ & $\begin{array}{l}1 \\
11\end{array}$ & $\begin{array}{l}0,686311312 \\
0,019693546 \\
11\end{array}$ \\
\hline & $\begin{array}{l}\text { Pearson } \\
\text { Correlation }\end{array}$ & 0,618031211 & 0,31722056 & 0,671508 & 0,696443 & 0,703259 & 0,686311 & 1 \\
\hline \multirow{2}{*}{ Pelabuhan } & Sig. (2-tailed) & 0,042710611 & 0,34183978 & 0,023659 & 0,017269 & 0,015763 & 0,019694 & \\
\hline & $\mathrm{N}$ & 11 & 11 & 11 & 11 & 11 & 11 & 11 \\
\hline
\end{tabular}

${ }^{*}$ Correlation is significant at the 0.05 level (2-tailed).

${ }^{* *}$ Correlation is significant at the 0.01 level (2-tailed).

sejauh 3 mil. Apalagi ada aturan yang membolehkan negara asing bisa menangkap ikan di wilayah ZEE, jika produksi aktual lebih rendah.

Pengadaan bantuan INKA MINA jika berupa kapal yang lebih besar dan mesin yang berteknologi tinggi tentu saja produksi aktual akan digenjot, sehingga tidak ada celah hukum untuk nelayan asing untuk menangkap ikan di wilayah Indonesia. Selain faktor kedekatan jarak, illegal fishing di wilayah perbatasan karena lemahnya teknologi yang digunakan masyarakat perbatasan. Permasalahan illegal fishing yang terjadi di Kecamatan Bunguran Barat dilakukan oleh nelayan Vietnam, di Kecamatan Nunukan dilakukan oleh nelayan Malaysia, dan di Kecamatan Nanusa dilakukan oleh nelayan Filipina.

\section{Analisis Regresi}

(1) Uji F untuk signifikasi menyeluruh

Uji F untuk signifikan menyeluruh bisa dilihat dari uji Anova atau $\mathrm{F}$ test, dimana diperoleh nilai F Hitung sebesar 11,59 dengan probabilitas 0,016 . Model regresi dapat digunakan untuk memprediksi jumlah kapal bantuan atau dengan kata lain bahwa (jumlah pelabuhan, potensi sumber daya ikan. Kelompok Usaha Bersama (KUB), jumlah kapal, tingkat produksi, dan jumlah nelayan) secara bersama-sama berpengaruh terhadap jumlah alokasi kapal bantuan 30 GT. Hal ini disebabkan nilai probabilitas jauh lebih kecil dari 0,05, yaitu hanya 0,016, terlihat dalam Tabel 2 .

Hal ini mengindikasikan bahwa keputusan DJPT dalam pemberian bantuan kapal (dari segi jumlah) tidak salah secara analisis statistik. Proses penetapan jumlah alokasi kapal pada suatu daerah menurut DJPT tidak dilakukan secara top down, dimana DJPT juga meminta usulan dari kabupaten dan dari provinsi. Tentu saja usulan ini juga disesuaikan dengan persyaratan lainnya, seperti melihat ketersediaan sumber daya ikan, dukungan dari Pemda, kepadatan nelayan, terdapat pelabuhan untuk 
Tabel 2. Uji F untuk Signifikasi Menyeluruh ANOVA(b)

\begin{tabular}{llccccc}
\hline \multicolumn{1}{c}{ Model } & Sum of Squares & df & Mean Square & F & Sig. \\
\hline & Regression & 128302,9871 & 6 & 21383,83119 & 11,59656 & 0,01647297 \\
& Residual & 7375,921959 & 4 & 1843,98049 & & \\
& Total & 135678,9091 & 10 & & & \\
\hline a & Predictors: (Constant), Pelabuhan, Potensi, KUB, Kapal, Produksi, Nelayan & & \\
b $\quad$ Dependent Variable: Jumlahbantuan & & & & \\
Sumber:Data diolah, 2012 &
\end{tabular}

kapal 30 GT ke atas, dan berada di kawasan yang berbasis industrialisasi perikanan tangkap.

\section{(2) Uji Koefisien Determinasi}

Hasil analisis mengindikasikan bahwa korelasi antara jumlah kapal bantuan 30 GT dengan variabel yang mempengaruhinya adalah sangat kuat, karena Angka R sebesar 0,972 (Angka R > 0,5 ). Adapun variabel yang mempengaruhinya (independent) adalah jumlah pelabuhan, potensi sumber daya ikan, Kelompok Usaha Bersama (KUB), jumlah kapal, tingkat produksi, dan jumlah nelayan. Implikasinya adalah jumlah program kapal bantuan 30 GT tiap wilayah sudah sesuai dengan jumlah variabel pembentuknya, artinya variebel yang ditetapkan DJPT dalam penetapan jumlah kapal bantuan dalam suatu lokasi sudah memenuhi persyaratan yang ada dalam Juknis, terlihat dalam Tabel 3.

Hasil analisis lain dari uji ini adalah koefisien determinasi yang mengindikasikan 0,9456 dan adjusted $\mathrm{r}$ square sebesar 0,864 (artinya $86,4 \%$ variasi jumlah kapal bantuan dalam suatu lokasi dapat dijelaskan oleh 6 variabel independent). Artinya, jumlah kapal bantuan yang diberikan pada suatu lokasi sudah memenuhi unsur-unsur yang ditetapkan Juknis, yaitu jumlah pelabuhan, potensi sumber daya ikan, Kelompok Usaha Bersama (KUB), jumlah kapal, tingkat produksi, dan jumlah nelayan. Hal ini juga diakui oleh Dinas Kelautan dan Perikanan
Pelabuhan Ratu, dimana sebelum mendapatkan bantuan 2 kapal pada tahun 2011 dan 2 kapal pada tahun 2012, sebelumnya dari pihak dinas Kabupaten mengajukan alokasi kapal ke pihak provinsi Jawa Barat. Selanjutnya pihak provinsi Jawa Barat mengajukan alokasi bantuan untuk masing-masing kabupaten ke Kementerian Kelautan Perikanan melalui Direktorat Jenderal Perikanan Tangkap. Pihak Dinas Kelautan dan Perikanan juga menambahkan bahwa tidak ada permainan uang dalam alokasi bantuan pada suatu kabupaten, baik itu dari pihak Provinsi maupun pihak DJPT. Kabupaten Pelabuhan Ratu pada tahun 2010 mengajukan 6 jumlah kapal 30 GT yang dibutuhkan, dan sampai tahun 2012 sudah mendapatkan bantuan 4 kapal.

\section{Permasalahan Utama Program Kapal Inka Mina}

Banyaknya kapal bantuan baik yang diserahkan pada tahun 2010 maupun tahun 2011 yang tidak beroperasi pada tahun 2012. Hal ini disebabkan beberapa masalah, misalnya masalah perizinan, masalah alat tangkap, masalah penyempurnaan kapal $(14,58 \%)$, masalah pengukuran ulang kapal $(10,42 \%)$, dan masalah kapal yang belum sampai lokasi $(16,67 \%)$. Berdasarkan hasil analisis, peneliti dapat mengungkapkan ada korelasi yang kuat (di atas 0,5) antara jumlah pemberian bantuan dengan faktor yang mempengaruhinya seperti yang

Tabel 3. Koefisien Determinasi

\begin{tabular}{cccccccccccccc}
\hline Model & $\mathbf{R}$ & R Square & $\begin{array}{c}\text { Adjusted } \\
\text { R Square }\end{array}$ & $\begin{array}{c}\text { Std. Error of } \\
\text { the Estimate }\end{array}$ & $\begin{array}{c}\text { Change } \\
\text { Statistics }\end{array}$ & Durbin-Watson \\
\hline & & & & & $\begin{array}{c}\text { R Square } \\
\text { Change }\end{array}$ & F Change & df1 & df2 & Sig. F Change \\
1 & 0,972 & 0,9456 & 0,864092326 & 42,941594 & 0,945636931 & 11,59656 & 6 & 4 & 0,01647297 & 3,090446349 \\
\hline
\end{tabular}

a. Predictors: (Constant), Pelabuhan, Potensi, KUB, Kapal, Produksi, Nelayan

b. Dependent Variable: Jumlahbantuan

Sumber:Data diolah, 2012 
ditetapkan DJPT, seperti potensi perikanan pada setiap daerah, jumlah nelayan, jumlah produksi, jumlah kapal, jumlah KUB (Kelompok Usaha Bersama), pelabuhan perikanan (Tabel 1). Korelasi yang kuat belum tentu menentukan keberhasilan program ini. Hal ini ini disebabkan ada faktor lainnya yang belum dipertimbangkan (faktor kualitatif) oleh DJPT, seperti budaya one day fishing pada masyarakat pesisir, kebiasaan masyarakat (alat tangkap dan ukuran kapal), transfer knowledge, dan faktor lainnya. Tidak dimasukannya faktor kualitatif tersebut menyebabkan banyak kapal bantuan yang sudah diserahterimakan dijalankan oleh nelayan dari wilayah lain karena nelayan penerima bantuan tidak terbiasa dengan trip lama (6 bulan). Permasalahan lainnya adalah banyak kapal dan alat tangkap yang diserahkan tidak sesuai dengan kebiasaan penangkapan masyarakat (misalnya di Pelabuhan Ratu bantuan alat tangkap long line, sedangkan keahlian utama nelayan adalah payang, gill net, dan bagan). Penelitian ini memberikan hasil sajian berupa empat masalah utama yaitu:

\section{(1) Produktivitas kapal masih rendah}

Indek penggunaan kapal Inka Mina dari hasil analisis adalah berkisar antara 0,02 sampai 0,21. Dengan demikian, kapal Inka Mina tersebut kurang intensif digunakan nelayan untuk menangkap ikan. Artinya produktifitas kapal bantuan Inka Mina masih rendah yang disebabkan oleh hari operasi kapal masih rendah, ratarata 25,7 hari/trip. Bahkan ada kapal bantuan yang indeks hari operasinya sangat rendah $(9$ hari). Indeks hari operasinya yang sangat rendah ini disebabkan pertama oleh belum terbiasanya nelayan penerima bantuan dengan trip yang lama (6 bulan/trip). Mereka terbiasa dengan sistem one day fishing. Sedangkan kapal bantuan yang diserahkan adalah kapal yang memakan waktu cukup lama dalam satu kali trip. Bahkan banyak kapal bantuan yang sudah diserahterimakan dijalankan oleh nelayan dari wilayah lain karena nelayan penerima bantuan tidak terbiasa dengan trip lama.

(2) Keuntungan yang diterima masih rendah
Produktivitas yang rendah mengakibatkan R/C rata-rata kapal Inka Mina kurang dari 2. Artinya tingkat keuntungan yang diterima nelayan cukup rendah, hal ini disebabkan oleh hasil tangkapan yang kurang karena keterbatasan wilayah penangkapan. Wilayah penangkapan terbatas karena biaya operasional yang dibutuhkan untuk mencapai wilayah ZEEI dengan 6 bulan/trip adalah minimal Rp500 juta. Besarnya biaya operasional kapal tentu membatasi wilayah penangkapan (kurang dari 12 mil), padahal sasaran dari program ini mengoptimalkan potensi di ZEEI (200 mil).

(3) Kapal bantuan tahun 2010 dan tahun 2011 banyak yang tidak beroperasi

Persentase kapal bantuan 2010 yang tidak beroperasi mencapai $12 \%$, karena faktor teknis dan faktor manajemen pengelolaan kapal seperti faktor kestabilan kapal, ketiadaan biaya operasional, kerusakan mesin, dan kerusakan kapal. Inka Mina 40 yang disalurkan di Kota Baru tidak dapat beroperasi karena kapal yang dibuat tidak memiliki stabilitas yang baik, sehingga akan mengakibatkan kapal oleng bila dioperasikan, selain itu geladak kapal terlalu tinggi yang mengakibatkan sulit mengoperasikan alat tangkap purseine. Kapal bantuan 2011 yang tidak beroperasi sebesar $20 \%$ akibat permasalahan perizinan, alat tangkap, dan masalah lainnya. Berdasarkan hasil monitoring per 3 November 2012, ada 6 kapal yang disalurkan pada tahun 2010 tidak dapat beroperasi, seperti di Kalimantan Selatan (Kota Baru), Papua Barat (Sorong dan Manokwari), Sumbar (Pesisir Selatan), Nusa Tenggara Timur (Ende), dan Maluku Tenggara.

(4) Ketidaksesuaian Juknis dan Realitasnya Pertama adalah ketidaksesuaian KUB pengelola, dimana tidak adanya keinginan kuat dari KUB untuk mengoperasikan kapal. Di Pelabuhan Ratu semua ABK-nya adalah dari luar wilayah. Hal ini disebabkan karena nelayan penerima bantuan tidak terbiasa dengan trip lama (6 bulan). 


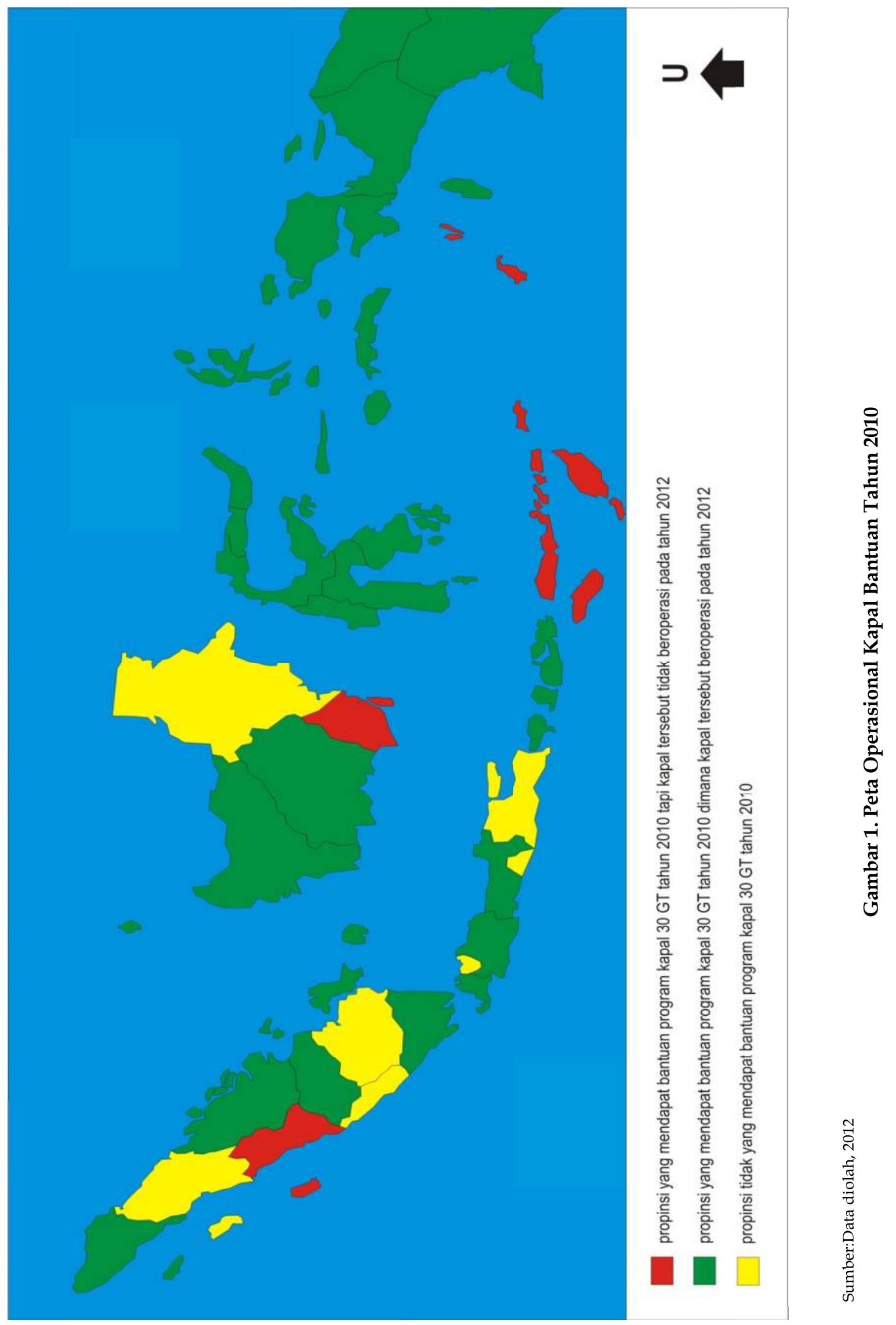




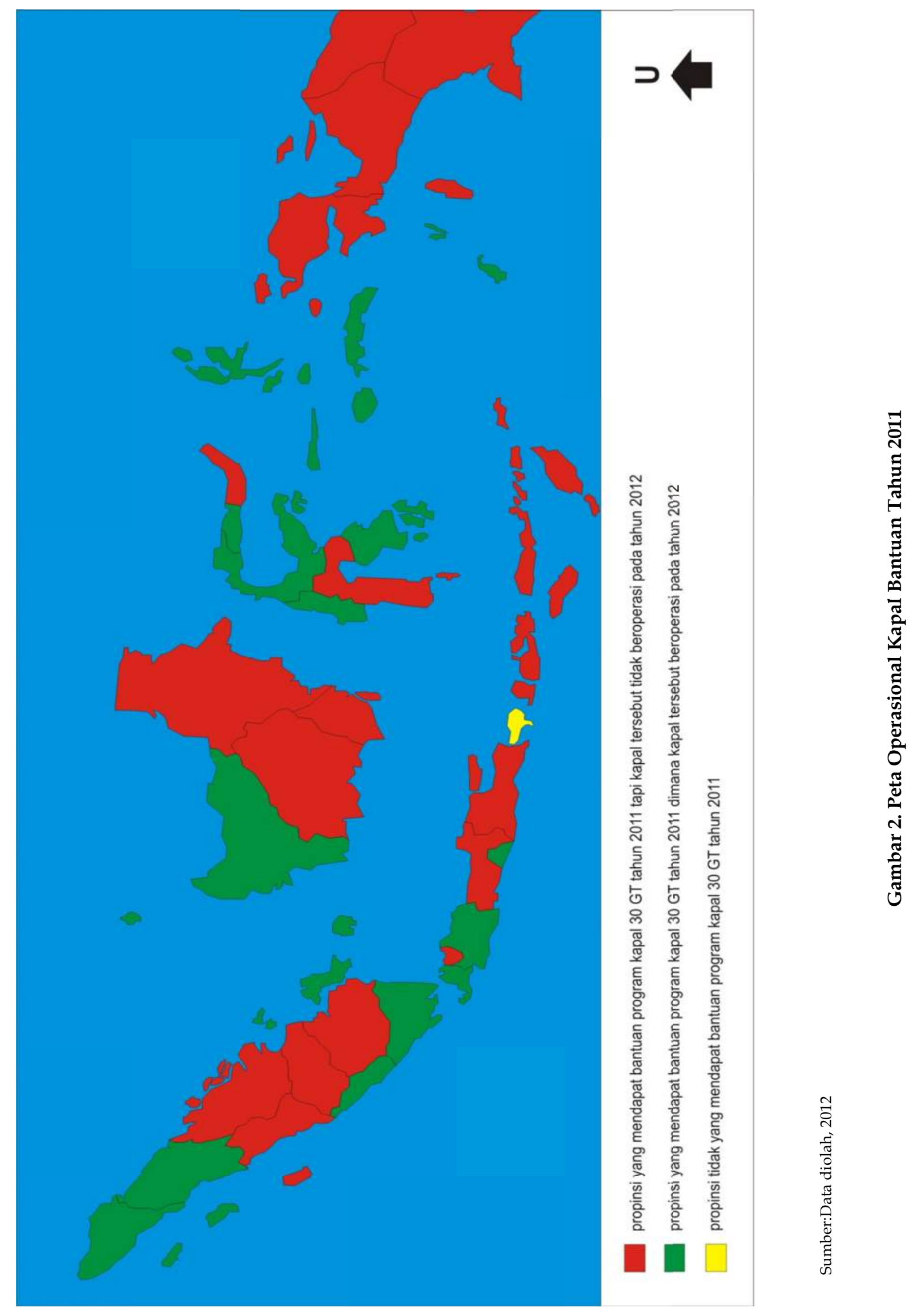


Permasalahan lainnya adalah banyak kapal dan alat tangkap yang diserahkan tidak sesuai dengan kebiasaan penangkapan masyarakat (misalnya di Pelabuhan Ratu bantuan alat tangkap long line, sedangkan keahlian utama nelayan adalah payang, gill net, dan bagan).

\section{Assessment untuk Permasalahan}

Untuk mencapai tujuan program kapal 30, yaitu mengoptimalkan upaya penangkapan optimal, maka harus dibuat assessment yang dioperasionalkan melalui tahapan implikasi kebijakan sebagaimana tertera pada assessment di bawah ini:

1. Assessment untuk peningkatan produktifitas kapal

Produktifitas kapal rendah karena bantuan kapal dan alat tangkap tidak sesuai dengan kebiasaan masyarakat sehingga indeks hari operasi pasar rendah. Selain itu juga disebabkan oleh rendahnya modal yang dimiliki KUB pengelola. Untuk kapal bantuan yang tidak sesuai dengan kebiasaan masyarakat (one day fishing) untuk tahap pertama memang harus mengambil dari wilayah lain, tapi jumlah ABK dari wilayah lain harus dikurangi bertahap. Pengurangan bertahap ini biar KUB pengelola bisa mengoperasionalkan kapal secara mandiri tidak secara terus-terusan mengambil ABK dari wilayah lain. Selain itu ABK diutamakan dari satu suku untuk menghindari konflik dan kebentahan untuk berlayar (60 hari). Di Papua misalnya, KUB penerima diganti ke KUB yang anggotanya merupakan campuran dari orang Bugis, Makasar, Jawa, dan orang Papua sendiri. Pergantian ini juga atas alasan, jika KUB penerima anggotanya bukan asimilasi, terutama nelayan dari orang Papua sendiri, dikuatirkan mereka tidak mampu mengelolanya. Hal ini disebabkan sebelumnya dikelola oleh KUB yang anggotanya semuanya orang Papua. Orang Papua tidak terbiasa dengan budaya melaut satu kali trip yang membutuhkan waktu 6 bulan, biasanya mereka hanya melaut dengan sistem one day fishing (ODF). Apalagi budaya orang papua yang terkenal malas juga dikuatirkan menghambat pelaksanaan program ini. Guna mengatasi masalah ini, KUB dipindahkan dari sebelumnya yang anggotanya semua Papua ke KUB yang anggotanya merupakan asimilasi dari berbagai suku (Bugis, Makasar, dan Jawa). Asimilasi ini diharapkan mampu menularkan etos kerja dan budaya melaut yang jauh ( 6 bulan satu kali trip) dari orang Bugis ke orang Papua. Assessment terhadap permasalahan ini adalah Anggota KUB harus bersedia menjadi ABK untuk transfer knowledge teknologi penangkapan yang lebih besar (30 GT) dengan sistem pergantian (misalnya 5 anggota pada trip pertama, dan 5 yang lainnya pada trip kedua.

\section{Assessment untuk peningkatan keuntungan} usaha

Keuntungan usaha rendah karena produktitas kapal rendah. Hal ini disebabkan oleh terbatasnya wilayah penangkapan karena tingginya biaya operasional sekali trip. Perluasan wilayah penangkapan dengan assessment peningkatan modal usaha KUB pengelola dengan sistem bapak angkat. Selain itu juga mengutamakan lokasi bantuan kapal yang masih memiliki potensi sumber daya ikan misalnya daerah perbatasan yang selama ini menjadi praktek illegal fishing. Berdasarkan data yang ada, contohnya untuk lokasi Kabupaten Natuna tidak ada bantuan terkait program tersebut sejak tahun 2010 hingga 2012. Pengutamaan wilayah perbatasan juga selaras dengan tujuan program Inka Mina yaitu mengoptimalkan penangkapan di wilayah ZEEI, terutama di wilayah perbatasan yang selama ini banyak menjadi praktek illegal fishing. Saat ini dengan perahu nelayan di wilayah perbatasan yang ukuran hanya 5 GT maka wilayah penangkapan hanya sejauh 3 mil. Apalagi ada aturan yang membolehkan negara asing bisa menangkap ikan di wilayah ZEE, jika produksi aktual lebih rendah. Misalnya ada bantuan Inka Mina berupa kapal yang lebih besar dan mesin yang berteknologi tinggi tentu saja produksi aktual akan digenjot, sehingga tidak ada celah hukum untuk nelayan asing untuk menangkap ikan di wilayah Indonesia. Selain faktor kedekatan jarak, illegal fishing di wilayah perbatasan karena lemahnya teknologi yang digunakan masyarakat perbatasan. Permasalahan illegal fishing yang terjadi di Kecamatan Bunguran Barat dilakukan oleh nelayan Vietnam, di Kecamatan Nunukan dilakukan oleh nelayan Malaysia, dan di Kecamatan Nanusa dilakukan 
oleh nelayan Filipina. Selain itu penyebab indek hari operasi kapal masih rendah adalah besarnya biaya operasional yang dibutuhkan satu kali trip (6 bulan) dimana minimal Rp500 juta. Padahal di sisi lain KUB penerima bantuan memiliki modal terbatas. Permasalahan ini bisa diassessment dengan bermitra dengan pihak lain misalnya dengan sistem bapak angkat. Akan lebih baik lagi kemitraan tersebut pada tahap penjualan sehingga harga yang diterima adalah harga ekspor.

3. Assessment untuk permasalahan banyaknya kapal yang tidak beroperasi

Untuk masalah ketiadaan biaya operasional, kapal tersebut harus bekerjasama dengan koperasi atau dengan sistem bapak angkat. Biaya operasional untuk kapal 30 GT sekali trip sangat tinggi (Rp 500 juta), sehingga dibutuhkan pihak ketiga untuk menalangi kegiatan operasional. Sistem bapak angkat ini tidak hanya mengurus masalah biaya operasional juga masalah penjualan hasil tangkapan. Misalnya Bapak angkat dari KUB DAFA di Pelabuhan Ratu adalah seorang eksportir, sehingga harga yang diperoleh oleh KUB adalah harga ekspor. Dalam penentuan harga, tidak hanya ditentukan oleh bapak angkat, pihak KUB juga memiliki "power", di mana pihak KUB mengecek harga melalui harga ekspor dari pedagang lainnya. Sedangkan permasalahan teknis seperti kerusakan kapal dan ketidak sesuaian kapal. Selain itu, selama proses pembuatan kapal harus ada pihak pengawas yang dalam hal ini KUB (Kelompok Usaha Bersama) yang diwakili oleh pihak Dinas Kelautan dan Perikanan terkait mengontrol pengawasan pembuatan kapal. Pengontrolon dalam proses pembuatan kapal ini dilakukan supaya spesifikasi kapal yang dibuat sesuai dengan preferensi pengguna, misalnya preferensi pengguna terhadap bahan kayu. Selain itu, faktor yang harus dipertimbangkan dalam pembuatan kapal dan harus dikontrol oleh pihak Dinas Kelautan dan Perikanan yang menyalurkan bantuan kapal adalah kesesuaian teknis kapal dengan alat tangkap yang digunakan. Hal ini dilakukan supaya tidak terulang lagi kasus kapal bantuan tidak dapat digunakan karena alasan geladak kapal yang dibuat terlalu tinggi sehingga tidak sesuai dengan alat tangkap purseine. Padahal alat tangkap yang digunakan untuk program kapal bantuan pada umumnya adalah purseine, handline, dan lainlain. Alat-alat tangkap ini digunakan untuk memanfaatkan sumberdaya perikanan pelagis besar. Selain itu, lokasi pembuatan kapal harus dekat lokasi penerima bantuan supaya mudah dalam pengawasan kapal.

4. Assessment ketidaksesuaian Juknis dengan Realitas

Sebelum kapal diserahkan minimal ada sosialisasi tiga kali. Selain itu harus ada Assessment lainnya yaitu penguatan kelembagaan melalui pembinaan dan pelatihan terhadap KUB penerima minimal 2 kali setahun. Selama ini belum ada penguatan kelembagaan untuk menyadarkan penerima bantuan terhadap kepatuhan Juknis.

\section{Simpulan}

Berdasarkan hasil analisis korelasi dapat disimpulkan ada korelasi yang kuat (di atas 0,5) antara jumlah pemberian bantuan dengan faktor yang mempengaruhinya seperti yang ditetapkan DJPT, seperti potensi perikanan pada setiap daerah, jumlah nelayan, jumlah produksi, jumlah kapal, jumlah KUB (Kelompok Usaha Bersama), pelabuhan perikanan. Namun korelasi yang kuat belum tentu menentukan keberhasilan program ini. Hal ini ini disebabkan ada faktor lainnya yang belum dipertimbangkan (faktor kualitatif) oleh DJPT, seperti budaya one day fishing pada masyarakat pesisir, kebiasaan masyarakat (alat tangkap dan ukuran kapal), transfer knowledge, dan faktor lainnya.

Faktor kualitatif tersebut tidak dimasukkan menyebabkan banyak kapal bantuan yang sudah diserahterimakan, dijalankan oleh nelayan dari wilayah lain karena nelayan penerima bantuan tidak terbiasa dengan trip lama (6 bulan). Permasalahan lainnya adalah banyak kapal dan alat tangkap yang diserahkan tidak sesuai dengan kebiasaan penangkapan masyarakat (misalnya di Pelabuhan Ratu bantuan alat tangkap long line, sedangkan keahlian utama nelaya adalah payang, gill net, dan bagan).

Assessment terhadap permasalahan ini adalah DJPT harus memasukan unsur kebiasan 
masyarakat (alat tangkap, ukuran kapal, dan lama trip). Assessment lainnya adalah penguatan kelembagaan melalui pembinaan dan pelatihan terhadap KUB penerima minimal 2 kali setahun, dan menyisihkan 30 persen dari pendapatan untuk saving yang nantinya ditujukan biaya pemeliharaan dan suatu investasi untuk kapal lainya bila umur teknis kapal bantuan sudah habis, dan kerja sama dengan bapak angkat tidak hanya untuk biaya operasional tapi juga untuk penjualan sehingga harga yang diterima bisa harga ekspor.

Permasalahan tersebut membuat produktivitas kapal bantuan rendah yang diindikasikan dengan indeks operasi kapal bantuan Inka Mina hanya berkisar 0,02 dan sampai 0,21, artinya kapal Inka Mina kurang intensif digunakan. Produktivitas yang rendah mengakibatkan R/C rata-rata kapal Inka Mina kurang dari 2. Bahkan pada tahun 2012, kapal bantuan tahun 2010 tidak dapat beroperasi sebesar 12\% dan kapal bantuan 2011 sebesar $20 \%$, dimana disebabkan oleh masalah perizinan

\section{Daftar Pustaka}

Gasperz.1992. Teknik Analisis dalam Penelitian Percobaan, Edisi ke-2. Bandung: Tarsito.

Ghozali, Imam. 2005. Aplikasi Analisis Multivariate dengan Program SPSS, Edisi ke-3. Semarang: Badan Penerbit-Undip.

Gittinger dan Adler. 1993. Evaluasi Proyek. PT Jakarta: Rineka Cipta.

Ibrahim, Y. 1998. Studi Kelayakan Bisnis. Jakarta: Penerbit Rineb Cipta.

Kadariah, et. al. 1999. Pengantar Evaluasi Proyek. Lembaga Penerbit Fakultas Ekonomi Jakarta: Universitas Indonesia.

Santoso, S. 2001. Konsep dan Aplikasi SPSS. Jakarta: Elexmedia Komputindo.

Rahmawati, Mariana F. 2006. Analisis Kelayakan Finansial Usahatani Blimbing (Averrhoa carambola L.) (Studi Kasus di Desa Moyoketen, Kecamatan Boyolangu, Kabupaten Tulungagung). Skripsi FP-UB. Malang. 